\title{
Optical parameters of the film naturally formed on the surface of cadmium telluride single crystals
}

\author{
V.A.Odarych, L.V.Poperenko, I.V.Yurgelevych, \\ V.A.Gnatyuk*, Toru Aoki*
}

\author{
Faculty of Physics of T.Shevchenko National University of Kyiv, \\ 4 Academician Glushkov Ave., 03127 Kyiv, Ukraine \\ *V.Lashkaryov Institute of Semiconductor Physics of the National \\ Academy of Sciences of Ukraine, Prospekt Nauky 41, 03028 Kyiv, Ukraine \\ Research Institute of Electronics, Shizuoka University, 3-5-1 Johoku, \\ Naka-ku, Hamamatsu 432-8011, Japan
}

\section{Received November 2, 2012}

\begin{abstract}
Ellipsometric study of different surfaces of CdTe single crystals was carried out at a light wavelength of $632.8 \mathrm{~nm}$. CdTe(110) crystals with cleaved surfaces after long time storage under ambient air conditions, Cd- and Te-terminated faces of (111) oriented CdTe crystals aged at room temperature in air during different times and samples chemically etched in a $\mathrm{Br}-\mathrm{HBr}$ solution were investigated. The refraction and absorption indexes, and thickness of the films formed on the surface of different samples were obtained and the nature of these films was discussed. The ellipsometric measurement data have been well described by the two-layer model of a reflective system which includes (1) internal presumably pure Te layer with thickness of a few monoatomic layers and (2) external layer, probably $\mathrm{Cd}$ or $\mathrm{Te}$ oxide film of thickness from 5 to $10 \mathrm{~nm}$ depending on the time of storage in air.
\end{abstract}

На длине волны света 632.8 нм проведено эллипсометрические исследования поверхности монокристаллического теллурида кадмия, выдержанного в течение длительного времени при комнатной температуре в контакте с атмосферным воздухом. Исследованы поверхности (111) с выходом наружу атомов Cd или Те, поверхность (110) сколов и поверхность образцов, протравленных после длительного выдерживания на воздухе в $3 \%$ растворе $\mathrm{Br}$ в $\mathrm{HBr}$. Установлено, что наилучшим образом описывает эллипсометрические данные двухслойная модель отражающей системы, которая включает внутренний слой в предположении свободного теллура с толщиной от одного до двух моноатомных слоев и внешний слой оксида, возможно кадмия или теллура, с толщиной от 5 до 10 нм в зависимости от времени выдерживания на воздухе.

\section{Introduction}

In practical use of CdTe crystals as nuclear radiation detectors, solar cells, substrates and ones for other applications, it is essential to have a clean, structurally perfect and smooth surface before applying various technological procedures (doping, oxidation, passivation, electrode deposition, formation of ohmic or rectifying contacts, etc.). Chemical polishing etching is a common procedure to improve the state and structure of the CdTe surface. However, any surface treatment may be accompanied by morphology changes, structure deterioration and formation of an elastically deformed region or layers with residual internal stresses. Moreover, the different crystal 
faces differ in properties and may be variously sensitive to different treatments [1, 2]. Therefore, it is important to know how the applied technological procedure affects the state, structure and properties of the crystal surface. In particular the certain interest consists in a study of the behavior of the single crystals surface under action of atmospheric air.

The investigations of oxidation peculiarities of the cadmium telluride surface have been well developed. In particular the properties of CdTe surface layer at its staying in air atmosphere $[3,4]$, in vacuum after the controlled filling by oxygen [5], and during thermal oxidation of a surface $[6,7]$ have been researched. It was most often to determine a chemical content of the surface layer. It was found that on a surface of a single crystalline CdTe specimen due to its interconnection with external medium the films with different content as well as various optical properties and a thickness in dependence on previous surface treatment and oxidation conditions, in particular temperature, may be formed. Practically the investigations of the optical properties of the oxidized CdTe surface are absent. In our previous works $[8,9]$ it was found that the polar faces of CdTe(111) crystals are oxidized in atmosphere in different ways, in particular the thickness of the film formed on Cd-terminated surface is greater than that on Te-terminated one.

The main aim of the current work consists in an application of an improved approach to a solution of reversal task of ellipsometry with appropriate modeling of surface reflective system in connection with interpretation of experimental polarimetric data for the determination of the optical constants and the thickness of natural oxidic film on Cd- and Te-terminated surfaces of CdTe single crystalline (111).

\section{Experimental}

The objects of the investigations were commercial (111) oriented semiconductor CdTe single crystals produced by Acrorad Corporation. Semi-insulating Cl-compensated CdTe ingots were grown by the travelling heater method and then were sliced into wafers and polished by the manufacturer. These wafers of single crystal CdTe differ from others in such manner that in a direction (111) the layers of $\mathrm{Cd}$ and $\mathrm{Te}$ atoms are followed by each others. We were provided with CdTe(111) samples with dimensions of $5 \times 5 \times 0.5 \mathrm{~mm}^{3}$. The $\mathrm{CdTe}(111)$ crystals have two polar surfaces namely so called A face (Cd-terminated) and B face (Te-terminated). The crystals after storage under ambient air conditions were used. Therefore the ellipsometric measurements were carried out on two opposite sides of CdTe crystals namely (111)A face and (111)B face of each sample covered by natural oxidic film. As an object of research the same sample subjected to chemical etching and wafers of the single crystal CdTe (110) treated by air atmosphere during long period including some months as well as some years were used too. Chemical etching of CdTe crystals was carried out in $3 \% \mathrm{Br}-$ $\mathrm{HBr}$ solution and then the samples were thoroughly rinsed in methanol. Before measurements all initial samples were washed in acetone and methanol.

The optical properties of CdTe single crystals were studied at two incidence angle $65^{\circ}$ and $72^{\circ}$. The ellipsometric parameters such as a phase shift $\Delta$ between the orthogonal components of a polarization vector and an azimuth $\psi$ (Arc Tangenta of ratio for the coefficients of an amplitude reflectance in $p$ - and $s$-planes of specimen surface) were obtained by using a laser ellipsometer LEF3M-1 (manufactured by Institute of Semiconductor Physics of SB RAS, Novosibirsk, Russia and Device Production Plant, Feodosia, Ukraine) with $\mathrm{He}-\mathrm{Ne}$ laser wavelength $\lambda=632.8 \mathrm{~nm}$. The inaccuracies of the measured data were following as $\delta \Delta=$ $1-1.5^{\circ}$ and $\delta \psi=0.02-0.07^{\circ}$. The obtained values of $\Delta$ and $\psi$ for different samples were interpreted in terms based on the models of a single thin film and two homogeneous layers located on an absorbing substrate $[10,11]$. The refraction $n$ and absorption $\kappa$ indexes as well as a thickness $d$ of the film were calculated on the base of the fundamental ellipsometric equation using the developed program [12]. The appropriate optical constants of CdTe substrate $n_{s}=3.04$ and $\kappa_{s}=0.29$ were taken from the literature [13]. The values $n, \kappa$ and thickness $d$ of the modified surface layer were obtained for both Cd- or Te-terminated sides of every sample, and for the samples after chemical etching and cleavage of the crystal planes as well.

\section{Obtained results}

In Fig. 1 the measured ellipsometric parameters at the light incidence angles $\varphi=72^{\circ}$ and $65^{\circ}$ for two opposite sides (A face or 

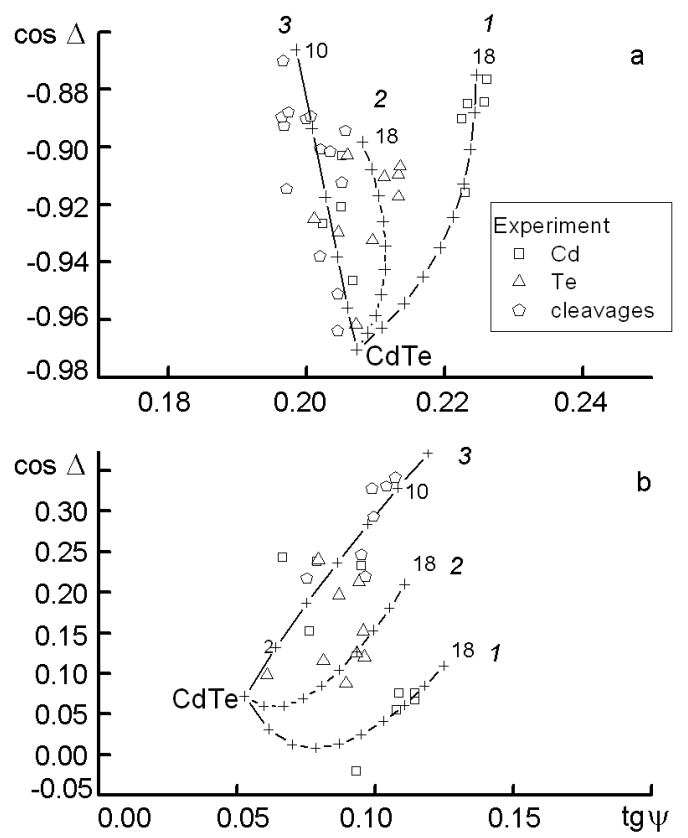

Fig. 1. Comparison of the experimental values of ellipsometric parameters $\cos \Delta$ and $\operatorname{tg} \psi$ (the symbols) obtained for the incidence angles $65^{\circ}$ (a) and $72^{\circ}$ (b) with theoretical dependences of ellipsometric parameters on the film thickness (curves 1,2 and 3) calculated in framework of the one-layer model of a reflective system for various magnitudes of refraction $n$ and absorption $\kappa$ indexes (Table 1 ). The numbers near the marks within theoretical curves indicate the thickness of oxide film in nanometers (through each $2 \mathrm{~nm}$ ).

Cd-terminated side, curve 1) and (B face or Te-terminated side, curve 2) of the samples as well as for the samples after the chemical etching and the cleavage (curve 3) are shown. The initial point in Fig. 1 is indicated by "CdTe" and corresponds to the CdTe substrate. The value of $\cos \Delta$ and $\operatorname{tg} \psi$ of the substrate were calculated in terms based on the optical constants of a CdTe single crystal with perfect surface [13].

For the interpretation of the data obtained during first stage of the measurement we have applied the simplest model due to one-layer film. It is known from the theory of an absorbing layer $[10,11]$ that when a film with refraction and absorption indexes different from those ones for substrate, the ellipsometric parameters $\Delta$ and $\psi$ (in our case $\cos \Delta$ and $\operatorname{tg} \psi$ ) are changed from the point "CdTe" along some continuous curve (Fig. 1). Here, as it is seen in Fig. 1 the obtained experimental points are situated along three curves. In particular the points obtained for $\mathrm{Cd}$ - and Te-terminated sides of the sample are situated on two different curves 1 and 2. From another hand for the etching samples the points that characterize $\mathrm{Cd}$ - and Te-sides of the same sample are coincided with curve 3 . The points obtained for the aged CdTe cleavage get this curve too. It can be assume that concrete own values of optical constants correspond to each of curves as well as appropriate thickness of the film corresponds to each point on the curve.

Thus, the parameters of the reflecting system, which should be determined, are the refraction and the absorption indexes and the thickness of film. This task has been solved using the automated program package [12]. The reversal task of ellipsometry, i.e. a determination of the parameters of a reflective system in connection with measured values of the ellipsometric parameters in some cases permits multisignificant solutions namely some sets of system parameters for a given set of experimental magnitudes may exist. That is why the background of the results obtained in this work needs a detail analysis of the procedure of the parameter determination.

In the applied method [12] for each experimental point (the pair of the measured values $\cos \Delta$ and $\operatorname{tg} \psi$ ) by using automated program one calculates the sets of possible magnitudes of optical constants $n$ and $\kappa$ of the film varying the film thickness $d$. It is clear that when optical constants of the investigated object which correspond to various experimental points are the same then the obtained sets of data must be crossed, and the point of the cross gives the necessary pair of values $n$ and $\kappa$. The position of each experimental point on appropriate set area will give a magnitude of the film thickness which corresponds to this point.

The sets of possible values of necessary parameters of the reflecting system in Fig. 2 are presented by curves each of them is calculated on a base of the experimental data for certain sample from those presented in Fig. 1. Along each curve (so called thickness curve) the thickness is changing and then the set from three necessary film parameters corresponds to each point of the curve.

The detailed analysis of the results in Fig. 2 permits to make some preliminary conclusions.

1) The set of the experimental data for all investigated samples with different surfaces gives the full set of possible parame- 

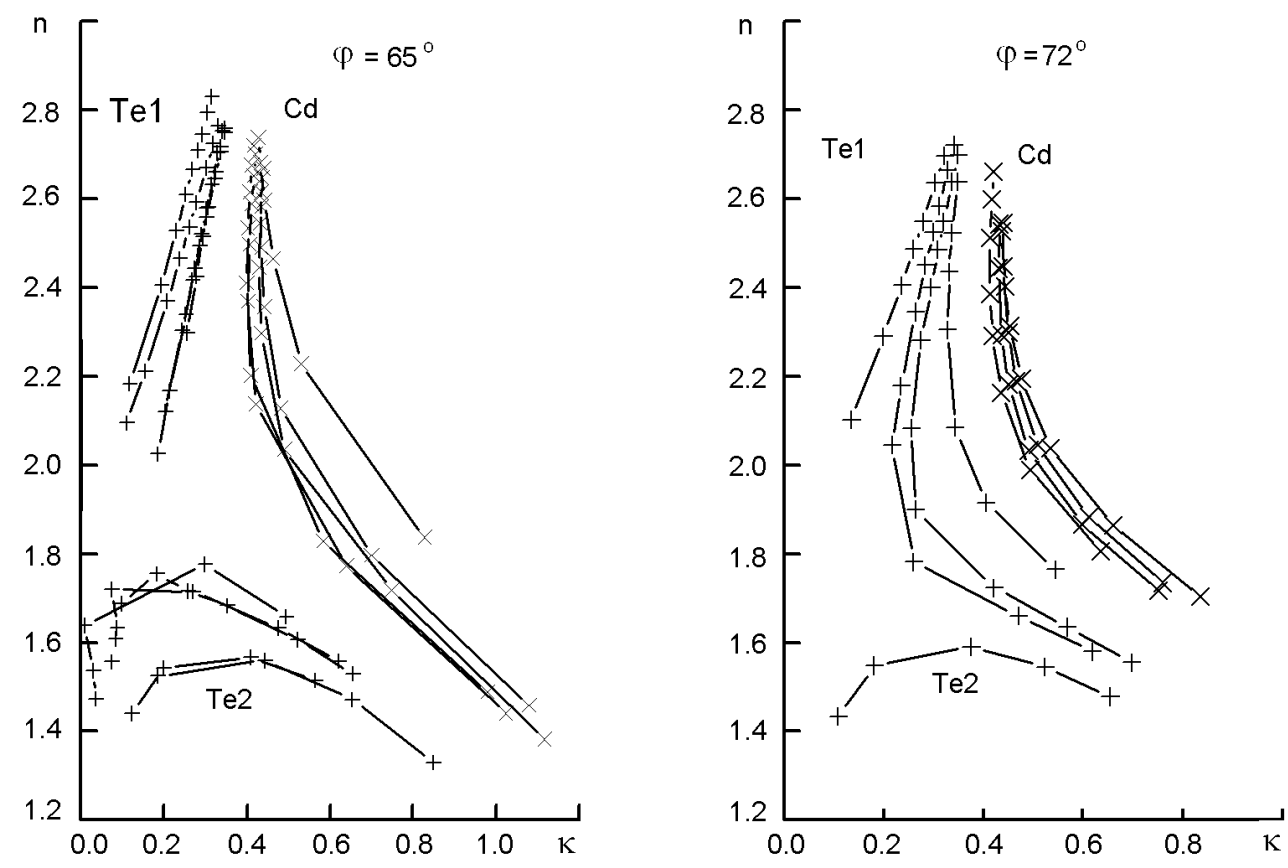

Fig. 2. Distribution of possible values of refraction $n$ and absorption $\kappa$ indexes obtained due to the experimental data presented in Fig. 1 for Cd- and Te-terminated surfaces of single crystalline CdTe. The curves $\mathrm{Te}_{2}$ present other possible solutions for $n$ and $\kappa$.

ters of a reflecting system as three groups of curves (curves $\mathrm{Cd}$, Te1 and Te2 in Fig. 2).

2) Thickness curves for Cd- and Te-surfaces do not cross. It noticed that optical constants of the surface layers for these two surfaces are different.

3) The group of curves Te2 represents other decouplings which arise only for some samples. That is why the sets of the values of the layer parameters which they represent in this case do not take into account as possible ones.

The parameters of the films were found by a consideration of the range of the nearest laying at the curves. The obtained results are shown in Table 1 . The theoretical curves calculated in terms based on the obtained layer parameters are in a good agree- ment with the experiment (Fig. 1). The films parameters found due to the experimental results for the samples which coincide with points on curve 3 in Fig. 1 were calculated in a model of a transparent film. In this case the refraction index and the film thickness were directly obtained in accordance with both measured ellipsometric parameters by means of automated program [12]. In Table 1 the values of the refraction index averaged by all samples data of this group are presented. The errors of the layer parameters were calculated as the root mean square within series (3-4 times) of the measurements carried out in the same way. The errors (the verified interval for verified probability 0.95 ) of the determination of the parameters are as following $\Delta n=0.05$,

Table 1. Values of refraction $n$ and absorption $\kappa$ indexes used for calculation of the theoretical curves presented in Fig. 1

\begin{tabular}{||c|c|c|c|c|c||}
\hline \hline The sample side & $\begin{array}{c}\text { The curve number } \\
\text { in Fig. 1 }\end{array}$ & $\begin{array}{c}\text { Incidence angle, } \\
\text { degree }\end{array}$ & $n$ & $\kappa$ & $\begin{array}{c}\text { Interval of } \\
\text { thicknesses, nm }\end{array}$ \\
\hline \multirow{2}{*}{ Cd } & 1 & 65 & 2.664 & 0.427 & $11-18$ \\
\cline { 2 - 6 } & 2 & 72 & 2.585 & 0.436 & $8-16$ \\
\hline \multirow{2}{*}{ Te } & \multirow{2}{*}{3} & 65 & 2.756 & 0.316 & $10-16$ \\
\cline { 2 - 6 } & - & 65 & 2.665 & 0.326 & $9-14$ \\
\hline \multirow{2}{*}{-} & 72 & 2.42 & 0 & $1-10$ \\
\hline
\end{tabular}


$\Delta \kappa=0.04, \Delta d=1-2 \mathrm{~nm}$. The significances of optical constants obtained from the measurements at the above-mentioned two angles of light incidence are the same within these errors.

It is seen (Fig. 1) that theoretical curves describe the distribution of experimental results well enough for all three curves. From Table 1 it is seen that in a whole Te-terminated side of the samples investigated possesses greater refraction index as well as smaller absorption index in comparison with appropriate magnitudes for Cd-terminated surface. The film thickness of the Cd-terminated surface succeeds one for the Te-terminated side of the sample and is greater more than some nanometers. The film thickness achieves the minimal value for the samples described by curve 3 (Fig. 1).

Thus the experimental results confirm that it is possible to create three groups among the specimens investigated.

The first group includes the specimens comparatively fresh ones staying in air atmosphere during less than several months. For them it is obtained that optical constants of the film grown in a result of staying in air under atmosphere condition depend on a type of the used side of the specimen namely what atoms of basic substance, Cd or Te, cover external surface of a single crystal (curves 1 and 2 in Fig. 1).

In second group of specimens which initially were produced in analogy to the first group, i.e. they possess the $\mathrm{Cd}$ - and Te-terminated surfaces but the specimens of this group have another prehistory which includes long staying in air atmosphere and chemical etching. For these samples it is obtained that optical constants of the film grown on both sides, namely the $\mathrm{Cd}$ - and Te-terminated are the same because the experimental points corresponding to these samples coincide within the same curve (curve 3 in Fig. 1).

Third group of specimens includes "aged" (110) single crystal cleavages of cadmium telluride which staying in air atmosphere conditions during long time namely one year and more. Optical constants of surface film for such cleavages coincide with those ones for specimens of second group. The experimental points for "aged" cleavages impact to curve 3 in Fig. 1 .

The difference in such behavior of the material with respect to its low temperature interaction with air atmosphere needs further explanation.

\section{Discussion}

Ellipsometry is not a method which permits to connect the parameters of the film with its chemical composition. In this case for an interpretation of the obtained results one may take into consideration only the known literature numerous data to make certain assumption due to a nature of the films investigated in this work.

The first fact found in this work is that the films on the surface of the investigated specimens of cadmium telluride are characterized by various values of optical constants. This result does not contradict to the existing data of other researchers. Namely in works [3-7] it was established that the parameters of the films (in particular their chemical composition) that grow on the surface of single crystalline CdTe due to a contact with air are determined by certain factors which reflect the state of previous treatment of the surface, the conditions of its oxidation (per esempio, the temperature) and details of its morphology. Likely an appearance of $\mathrm{Cd}$ or Te atoms on active surface of single crystal CdTe is one of such principal factors. In particular the efficiency of implementation of oxygen atoms into crystalline lattice is determined by the characteristics of the surface energetic barrier which these atoms succeed by implementing into crystalline lattice. The characteristics of such barrier are probably defined in particular by appropriate atoms filling of surface layer namely concrete type of atoms, in given case $\mathrm{Cd}$ or Te atoms, which are positioned on external surface of a single crystal. That is why it becomes clear that films formed on A and B faces of a single crystal investigated in this work may possess various values of the film parameters because they differ by composition of the upper surface layer.

On the surface of the etched samples and the surface of the aged cleavages the oxygen films are growing in the same manner and hence possess the same optical parameters which differ from those ones that characterize the films on $A$ and $B$ faces. This fact may be explained by that the surface of the best cleavage in plane (110) CdTe contains both $\mathrm{Cd}$ atoms and Te ones. Moreover a reflecting surface of the cleavage is characterized by the step view. From another hand one may suggest that during chemical etching the uncontrolled destroying of atomic bonds arises in such way that in some places on a crystal surface the atoms 
of one type occure in layer but in other its places the atoms of second type arise as well. In some sense the surface becomes as irregular one due to its composition. As a sequence a reflecting surface of both the cleavages and the etched samples possesses similar homogeneous distribution of $\mathrm{Cd}$ and Te atoms.

Another feature of the obtained data consists in a formation on A and B faces of (111) CdTe of absorbing films in opposite to an appearance of transparent films at the same light wavelength on a surface of the etched specimens and (110) cleavages, i.e. the content of the formed films is characterized by various chemical components. This fact as well as high significance of the absorption index are not agreed to applying the one-layer model for a description of the films formed on A and B faces of (111) CdTe single crystal. Actually by theoretical and experimental researches of a process of the interaction of the atoms on a surface of a single crystal CdTe with atmospheric oxygen it was found that oxydic compositions of cadmium as well as tellurium are formed. For example, in $[14,15]$ theoretical investigations based on a first principle calculation of pseudopotential method were carried out. The absorption of oxygen atoms through surface (110) CdTe was studied. It is found that interaction of oxygen atoms with basic material undergoes several stages. At the final stage the bond $\mathrm{Cd}-\mathrm{Te}$ is destroying and the complexes $\mathrm{Cd}-\mathrm{O}, \mathrm{Cd}-\mathrm{O}_{2}, \mathrm{Te}-\mathrm{O}$ (at high temperatures) or complexes of type $\mathrm{Cd}-\mathrm{O}-\mathrm{O}$ and $\mathrm{Cd}-\mathrm{O}_{2}$ are formed. The oxides of both cadmium and tellurium on a surface of cadmium telluride sample were observed experimentally as well. For example in [16] on a chemically modified surface CdTe the layers of $\mathrm{TeO}_{2}$ were found. In [5] the property of the selected oxidation of Te atoms on surface CdTe (111) and in subsurface range was found. The films CdTe oxidated in air atmosphere contain both $\mathrm{TeO}_{2}$ and $\mathrm{CdO}$ [4]. At a condition of thermal oxidation on the sample surface of CdTe single crystal under the action of oxygen a composition $\mathrm{CdTeO}_{3}$ was also found $[6,17,18]$. The peculiarity exists that each oxide from the above-mentioned ones does not absorb light in the visible spectra.

Then from possible cadmium oxides only $\mathrm{CdO}$ is the most stable $[19,20]$ in particular in connection with action of atmospheric factor. This oxide possesses semiconductor properties and its refraction index in single crystal state at light wavelength $671 \mathrm{~nm}$ is equal to $n=2.49$. Oxide compositions of tellurium exist like these $\mathrm{TeO}, \mathrm{TeO}_{2}, \mathrm{TeO}_{3}$ [19], their refraction index lies within interval 2.3-2.5 and the all materials are transparent or weakly colored ones. Thick films of cadmium oxide and double oxide of tellurium are transparent for light with wavelength (photon energy) of the presented research namely $1.96 \mathrm{eV}$. Moreover in accordance with [21] the optical interval for direct electron transitions in a case of the deposited films $\mathrm{TeO}_{2}$ is closed to $3.75 \mathrm{eV}$ and for the films CdO obtained by oxidation of cadmium one is surrounded at 2.2 [ 22 , 23] or $2.11 \mathrm{eV}$ [23].

For the etched samples and the aged cleavage we have observed the films which are transparent and possess the refraction index equal to 2.42 (see Table 1 ) that is well agreed with significance of 2.4 obtained by ellipsometric method at this light wavelength [23] for films $\mathrm{CdO}$.

Thus the films that are formed on CdTe sample surface due to its interconnection with atmospheric oxygen may contain such oxides as $\mathrm{CdO}$ and $\mathrm{TeO}_{2}$ or their mixture.

The obtained values of the absorption index of $0.3-0.4$ for surface oxide films of the samples with their strong positioning as a type of $A$ and $B$ faces in a case of a single crystal CdTe is characteristic for the allowed direct electron transitions that form the edge of fundamental absorption. For films CdO within this range only indirect electron transitions were attributed and appropriate significance of absorption index (in order of 0.05) was observed [23]. Thus on A and B-faces of cadmium telluride crystal the oxide films which may not be simple oxides of cadmium or tellurium as well as their mixture.

Also great significance of an absorption index may be a sequence of an addition of highly absorbing material into the bulk transparent oxide film in particular an appearance of each component of basic substance in oxygen deficit-like state. In [16] a presence of tellurium on the unmodified single crystal CdTe surfaces was registered and in [5] its elevated content as a pure component was detected on the surface of (111) CdTe cleaned by chemical method. The appearance of Te atoms in chemically free state may be a sequence of some reactions that occur on a surface as a result of its interaction with atmospheric oxygen.

Tellurium is a highly refractive and strongly light absorbing anisotropic material with trigonal structure and possesses 
the refraction index of about 6 and the absorption index exists in the interval of 2.74.6 at light wavelength within range of this research in the visible in dependence on an orientation of crystallographic axis [24]. Thus its presence in the bulk of the film medium in chemically free state must strongly influence optical constants of material in a whole. But at homogeneous disposal of Te atoms within a bulk of oxide film both the reflection index and the absorption index must only increase as compared to optical constants of basic material of this layer namely cadmium oxide and tellurium oxide. At the same time our results obtained for the refraction index of CdTe films are close to those values which are characteristic for $\mathrm{Cd}$ and $\mathrm{Te}$ oxides.

That is why the above-mentioned suggestions insist on a substitution of this simple model of a reflective system based on an existence of the homogeneous film on a surface of a single crystalline cadmium telluride. The additional source of criticism due to this simple model is the great values of the film thickness (Table 1). It is difficult to image that on the surface of a single crystal CdTe at the condition of low temperature oxidation the films with thickness of about $20 \mathrm{~nm}$ may be formed as it is obtained for the investigated samples in the framework of the used one-layer model.

During second stage of a treatment of the experimental data we have used more complex film morphology namely the twolayer model for its description. Having taken into consideration the fact of an existence of chemically free tellurium layer found in $[5,16]$ at certain condition we have supposed as the most probable such model that includes interstitial Te atoms layer between the surface (111) CdTe and thin film based $\mathrm{Cd}$ oxide as well as $\mathrm{Te}$ oxide. Accurate selection between these types of oxides is not possible because of both substances possess similar significances of the refraction index.

Usually in the two-layer model one defines the numeration of the layers beginning from the upper medium. Then $n_{1}, \kappa_{1}$ and $d_{1}$ correspond to optical constants and the film thickness respectively (in this case it's oxide layer), and $n_{2}, \kappa_{2}$ and $d_{2}$ are optical constants and the thickness of Te atoms layer respectively.

In Fig. 3 the results of the calculation within such two-layer model are presented in comparison with the same experimental data that are in Fig. 1 too. The numeration
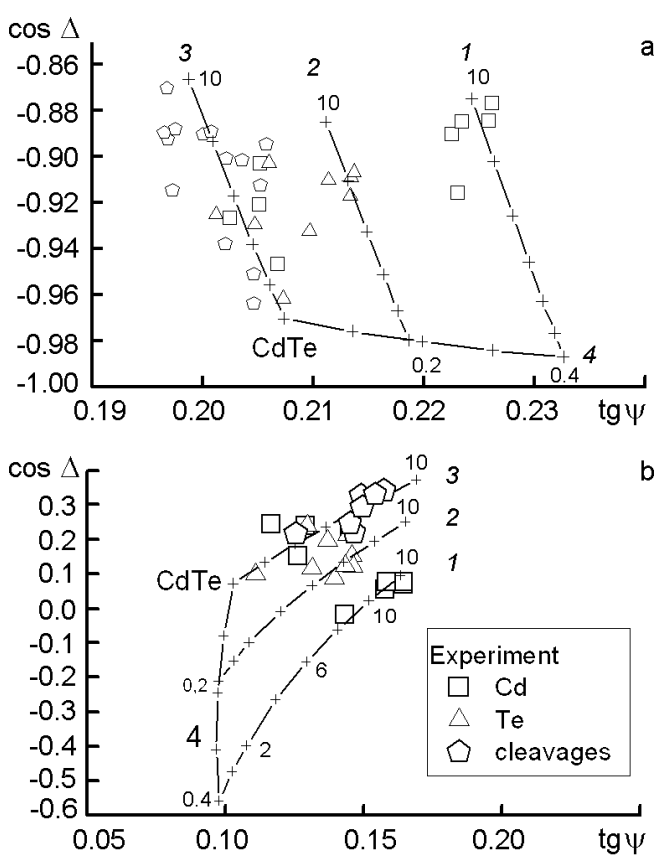

Fig. 3. Comparison of the experimental values of ellipsomeric parameters $\cos \Delta$ and $\operatorname{tg} \psi$ (the symbols) obtained for the incidence angles $65^{\circ}$ (a) and $72^{\circ}$ (b) with theoretical dependences of the ellipsometric parameters on the film thickness (curves 1, 2 and 3) calculated in framework of the two-layer model of a reflective system for various magnitudes of the refraction $n$ index (Table 2). The curve 4 corresponds to $\mathrm{Te}$ atoms layer on the substrate of a single crystalline cadmium telluride. The numbers near the marks within theoretical curves indicate the thickness of oxide film in nanometers.

of the curves $1-3$ is also served and curve 4 corresponds to the parameters for the layer of chemically free Te atoms on a surface of single crystalline CdTe, curves 2 and 3 describe the change of the thickness of external layer (oxide layer) laying above the $\mathrm{Te}$ atoms layer, curve 1 is a dependence of layer thickness change on the surface of sample CdTe where the interstitial layer of Te-riched medium is absent.

For optical constants of tellurim the significances averaged for two orientations of optical axes and presented in [24] were used. The parameters of the calculation of the curves are presented in Table 2. The notification $\Delta d_{1}$ concerns with area in which the thickness of oxidic film on a surface of the investigated samples is changed.

It is necessary to notice that only a calculation of the refraction index of the films on a surface of the etched samples and the 
Table 2. Refraction $n$ and absorption $\kappa$ indexes of the upper (using 1 as a low symbol in the numeration of the parameters of the layer) and the lower (low symbol as 2) layers used for calculation of the theoretical curves and presented in Fig. 3, and the thicknesses of appropriate layers founded in accordance with the positions of the experimental points relatively to the theoretical curves

\begin{tabular}{|c|c|c|c|c|c|c||}
\hline \hline Curve number & $n_{1}$ & $\kappa_{1}$ & $n_{2}$ & $\kappa_{2}$ & $d_{2}, \mathrm{~nm}$ & $\Delta d_{1}, \mathrm{~nm}$ \\
\hline 1 & 2.42 & 0 & 6.05 & 3.65 & 0.4 & $7-11$ \\
2 & 2.42 & 0 & 6.05 & 3.65 & 0.18 & $6-8$ \\
3 & 2.42 & 0 & & & & $1-10$ \\
4 & - & - & 6.05 & 3.65 & - & $0-0.4$ \\
\hline
\end{tabular}

cleavages of a single crystalline CdTe sample is reliably determined (curve 3 in Fig. 1 and Fig. 3). As it is seen (Table 2) for the investigated films comparatively great interval of the film thicknesses is overcoming in spite of essential calculation errors, and theoretical curve 1 describes well enough the positions of the experimental points. For the samples with A- and B-type of the surface it was not possible to obtain the experimental results with big number of samples at wide interval of a change of the thicknesses of surface film. That is why we have suggested that on these samples of a single crystal CdTe as compared to the etched ones and its cleavages the same surface film exists. Then in accordance with the positions of appropriate experimental points relatively to the curve 4 (it corresponds to Te atoms layer) one may determine for such Te-riched layer its thickness $d_{2}$ presented in Table 2 .

We suppose that the two-layer model with interstitial layer which contains nonbinding $\mathrm{Te}$ more preferable to describe our ellipsometric data in comparison to the onelayer model. In particular it is found that Te atoms layer essentially influences ellipsometric parameters of the light wave reflected. The thickness of this layer on Teterminated side of a single crystalline CdTe is equal to $0.18 \mathrm{~nm}$ that is close to monoatomic layer but on Cd-terminated side its thickness is 2 times greater, i.e. 2 monoatomic Te-riched layers are attributed to this A face of a single crystal CdTe sample.

It is possible to image that in a process of the interaction of the surface atoms of CdTe single crystal with atmospheric air oxygen atoms destroy the bonds between $\mathrm{Cd}$ and Te atoms in external layer forming the complexes with these atoms. Then after each such action the basic surface (111) CdTe remains unchanged and this oxide process repeats again for deeper layers on the surface of CdTe single crystal.

\section{Conclusions}

Application of the model of the two-layer film allowed us to describe successfully ellipsometric results obtained under study of the reflection of light from the different surfaces (Cd- and Te-terminated ones) of CdTe(111) single crystals as well as from surfaces of the chemically etched samples and cleavage surfaces of this crystal. In this two-layer system the external layer is the film of $\mathrm{Cd}$ or $\mathrm{Te}$ oxides and their mixture and the inner one adjacent to the substrate of single crystalline cadmium telluride is the layer of chemically unbinding Te. The refraction index of external layer is close to value of 2.42 for the all investigated samples and the film thickness is varied from 5 to $10 \mathrm{~nm}$ in dependence on staying time in air atmosphere. The thickness of the inner layer in an assumption of the presence of chemically free $\mathrm{Te}$ atoms within this layer on the surface of single crystalline cadmium telluride may be estimated for its Te-terminated surface as a value of one monoatomic layer $(0.18 \mathrm{~nm})$ in a contrary to Cd-terminated one where the thickness of Te atoms layer is about 2 monoatomic layers $(0.4 \mathrm{~nm})$.

Aknowlegment. Part of this work was performed in the framework of the Collaborative Project COCAE (grant agreement No 218000) of the European Community's Seventh Framework Programme (FP7/20072013).

\section{References}

1. V.A.Gnatyuk, T.Aoki, O.I.Vlasenko et al., Appl.Surf. Sci., 255, 9813 (2009).

2. K.Suzuki, H.Shiraki, IEEE Trans. Nucl.Sci., 56, 1712 (2009).

3. M.Hage-Ali, R.Stuck, A.N.Saxena et al., Appl. Phys., 19, 25 (1979). 
4. I.Fritsche, S.Gunst, E.Golusda et al., Thin Solid Films, 387, 161 (2001).

5. J.Kowalski, B.A.Orlowski, J.Ghijsen, Appl. Surf. Sci., 166, 237 (2000).

6. Muneyoshi Suita, Tsunemasa Taguchi, Nucl. Instrum. Meth. Phys. Res., 283, 268 (1989).

7. G.A.Ilchuk, V.I.Ivanov-Omskij et al., FTP, 9, 1099 (2000).

8. Toru Aoki, V.A.Gnatyuk, V.A.Odarych et al., in: Proc. 7th Intern. Conf. on Global Reaseach and Education in New Methods in Education Proceedings, Pech, Hungary (2008), p.468.

9. L.V.Poperenko, V.A.Gnatyuk, V.A.Odarych, T.Aoki, in: Proc. Intern. Workshop on Field Emitter and Semiconductor Materials and Devices, Shizuoka, Japan (2010), p.15.

10. R.M.A.Azzam, N.M.Bashara, Ellipsometry and Polarized Light, Elsevier Science Ltd, Amsterdam (1987).

11. L.V.Poperenko, V.S.Stashchuk, I.A.Shaikevych, V.A.Odarych, Diagnostics of Surface with Polarized Light, Kyiv University, Kyiv (2007) [in Ukrainian].

12. A.Z.Evmenova, V.A.Odarych, F.F.Sizov, M.V.Vuichyk, Optica Applicata, 38, 585 (2008).
13. Adachi Sadao, Kimura Toshifumi, Suzuki Norihiro, J.Appl. Phys., 74, 3435 (1993).

14. R.Miotto, F.D.Kiss, A.C.Ferraz, Surf. Science, 525, 24 (2003).

15. F.D.Kiss, A.C.Ferraz, Brazilian J.Phys, 36, 291 (2006).

16. D.N.Bose, S.Basu, K.C.Mandal, Thin Solid Films, 164, 13 (1988).

17. Fang Wang, A.Schwarthman, A.L.Fahrenburch et al., J.Appl. Phys., 62, 1469 (1987).

18. Z.K.Heiba, Cryst.Res.Technol., $\quad 38,488$ (2003).

19. Physical and Chemical Properties of Oxides, Spravochnik, Metallurgia, Moscow (1978) [in Russian].

20. A.E.Vol, I.K.Kagan, Structure and Properties of Double Metal Systems, v.4, Nauka, Moscow (1979) [in Russian].

21. Khalel Arshak, O. Korostynska, Sensors, 2, 347 (2002).

22. C.Dantus, G.G.Rusu, M.Dobromir, M.Rusu, Appl.Surff. Sci., 255, 2665 (2008).

23. S.G.Choi, J.Zun Iga-Perez, V.Munoz-Sanjjose et al., J.Vac.Sci.Technol., B28, 1120 (2010).

24. Handbook of Optical Constants of Solids, ed. by E.D.Palik, Acad. Press, Inc. (1991).

\section{Оптичні параметри природньої плівки на поверхні монокристалічного телуриду кадмію}

\section{В.А.Гнатюк, В.А.Одарич, Л.В.Поперенко, І.В.Юргелевич, Тору Аокі}

На довжині світлової хвилі 632.8 нм проведено еліпсометричні дослідження поверхні монокристалічного телуриду кадмію, витриманого протягом тривалого часу за кімнатної температури у контакті з атмосферним повітрям. Досліджено поверхні (111) із виходом назовні атомів $\mathrm{Cd}$ або Те, поверхня (110) сколів та поверхня зразків, протравлених після тривалого витримування на повітрі в $3 \%$ розчині $\mathrm{Br}$ в $\mathrm{HBr}$. Bстановлено, що найкраще описує еліпсометричні дані двошарова модель відбиваючої системи, яка включає внутрішній шар в припущенні вільного телуру з товщиною від одного до двох моноатомних шарів та зовнішній шар оксиду можливо кадмію чи телуру з товщиною від 5 до 10 нм в залежності від часу витримування на повітрі. 